\title{
HISTOPATHOLOGICAL ANALYSIS OF SCHISTOSOMA HAEMATOBIUM METAPLASIA OF THE URINARY BLADDER
}

\section{By}

\section{NOHA S. AHMED ${ }^{\star}$, SHEREN F. MAHMOUD ${ }^{2}$, ELNISR R. MOHAMED ${ }^{3}$} AND REFAAT M. KHALIFA ${ }^{4}$

Departments of Medical Parasitology ${ }^{1}$, Pathology ${ }^{2}$, Urology ${ }^{3}$, Faculty of Medicine, Sohag University and Department of Medical Parasitology ${ }^{4}$, Assiut University, Egypt (*Correspondence: nohasammer@yahoo.com)

\section{Abstract}

The present cross sectional study was carried out to analyze the histopathological changes in the urinary bladder affected by Schistosoma haematobium among 54 patients (aged between 20-60 years; 40 males, 14 females; 44 from rural, 10 from urban areas) attending Sohag University Hospital, Egypt from October 2015 to March 2016. 10\% formalin fixed biopsy specimens were examined from which sections of $5 \mu \mathrm{m}$ were prepared and examined microscopically. Mid-stream urine samples were collected from the patients after a slight physical exercise immediately transported to the Parasitological Laboratory to be examined for $S$. haematobium eggs. Histopathological examination revealed squamous metaplasia of the urinary bladder in 38/54 cases (70.4\%); $20 / 54$ (37\%) non- keratinizing metaplasia, $18 / 54$ (33.3\%) keratinizing metaplasia and invasive squamous carcinoma in 11/54 (20.4\%). It was concluded that Schistosoma haematobium is still one of the major risks of developing squamous cell metaplasia of the urinary bladder in Egypt which was found to be of high statistically significance in both males and females in rural areas. In this study, bladder squamous metaplasia was subdivided into non-keratinizing with less malignant potential, keratinizing with a definite affinity to carcinogenesis and invasive severe forms; but these subdivisions were found to be statistically not significant in relation to gender, age and locality, although they were of importance for the proper and successful management of the encountered cases. Keywords: Schistosoma haematobium, Histopathology, Urinary bladder, Squamous metaplasia

\section{Introduction}

Schistosomiasis is a complex of parasitic diseases with varied manifestations caused by different Schistosoma species.

Most cases of human schistosomiasis are caused by Schistosoma haematobium, Schistosoma mansoni, or Schistosoma japonicum (Shebel et al, 2012). Schistosomiasis is prevalent in tropical and subtropical areas, especially in poor communities without access to safe drinking water and adequate sanitation. Estimates show that at least 258 million people required preventive treatment for schistosomiasis in 2014; at least $90 \%$ of them live in Africa (WHO, 2016). Globally, 280,000 deaths were attributed to schistosomiasis annually in the African region alone (CDC, 2011).

Urinary tract disease develops after infection with Schistosoma haematobium and granulomatous inflammation in the response to deposition of eggs in tissues (Shebel et al, 2012). Urinary schistosemiasis results clinically in dysuria, haematuria, proteinuria, bladder calcification, sandy patches, ureteric obstruction, secondary bacterial infection in the urinary tract, renal colic, hydronephrosis, and renal failure (Gryseels et al, 2006, Barsoum, 2013; Barsoum et al, 2013). Epidemiological studies have associated chronic urinary schistosomiasis with squamous cell car-cinoma of the bladder in Egypt and other parts of Africa (El-Sebaie et al, 2005; Gryseels et al, 2006; Daniel and Blatt, 2016).

The aim of the present work was to study the schistosomal carcinogenic findings in the urinary bladder.

\section{Subjects and Methods}

The present cross sectional study was carried out from October 2015 to March 2016 on a total of 54 patients (Tab.1). 
Table 1: Patients gender, locality and age groups.

\begin{tabular}{|c|c|c|c|c|}
\hline Subject & \multicolumn{3}{|c|}{ Population examined } & Total \\
\hline & \multicolumn{2}{|c|}{ Male } & emale & $\mathrm{N} \%$ \\
\hline & 40 & & 14 & 54 \\
\hline Rural & 33 & & 11 & $44 \quad(81.5 \%)$ \\
\hline urban & 7 & & 3 & $10(18.5 \%)$ \\
\hline Age group & $20-35$ & $36-45$ & $46-60$ & \\
\hline Total & 8 & 19 & 27 & 54 \\
\hline
\end{tabular}

\section{Subjects and Methods}

Collection of tissue samples: 54 urinary bladder specimens were referred from Department of Urology Sohag University Hospital diagnosed as schistosomiasis at Pathology Laboratory of Sohag University Hospital through the period from October 2015 to March 2016 were examined to study the histopathological effect of $S$. haematobium on the cells of urinary bladder.

The research Team followed the ethical standards of confidentiality and freedom to participate. The respondents were informed that the study was voluntary and they were assured that their privacy would be protected and all of them gave a written consent for taking and studying the specimens.

Histological examination: Histopathological examination of specimens from the urinary bladder removed by transurethral resection and radical cystectomy. The specimens were fixed in $10 \%$ formalin. Sections of $5 \mu \mathrm{m}$ thickness were prepared with paraffin embedded tissue by using the standard histological techniques (Culling, 1993). Sections were stained with haematoxylin and eosin and mounted permanently in DPX and examined by the compound microscope. Microphotographs of the tissue sections were prepared for histological observations.

Urine collection and examination for Schistosoma haematobium eggs: Dark labeled sterile, plastic universal containers were given to the patients to collect midstream urine samples. This was done after a slight physical exercise. The urine collected was then immediately taken to the laboratory for examination. $10 \mathrm{ml}$ of the urine sample was centrifuged at $5000 \mathrm{rpm}$ for 5 minutes. The supernatant was discarded to leave sediment which was transferred to the center of a clean grease-free glass slide to which was added a cover slip. This was mounted on a light microscope and examined at $\times 40$ objective to identify $S$. haematobium eggs.

Statistical analysis: Statistical Package for the Social Science (SPSS) program (version 20) was used for grouping, tabulation and statistical analysis of the data. Sample characteristics were summarized using the mean and the standard deviation (SD) for continuous variables and percentage for categorical variables. Chi square test was used to estimate the difference and $\mathrm{P}$ value below 0.05 was considered significant.

\section{Results}

During the study period 54 patients were diagnosed pathologically with urinary bladder schistosomiasis. Urine analysis revealed the presence of $S$. haematobium eggs in all cases. All cases showed deposition of calcified $S$. haematobium eggs in the submucosa and even musculosa of the urinary bladder surrounded by granulomatous reaction containing large number of macrophages, lymphocytes, and eosinophils with fibrotic background.

Histopathological examination of biopsy specimens of the bladder lesions revealed squamous metaplasia of the urinary bladder in 38/54 cases (70.4\%), 20/54 (37\%) non keratinizing metaplasia (Plate I, 1) and 18/54 (33.3\%) keratinizing metaplasia (Plate I, 2), invasive squamous carcinoma in $11 / 54(20.4 \%)$ (Plate I, 3,4), at- 
rophied surface epithelium of the urinary bladder with formation of brunn's nests and cystitis cystic in $3 / 54$ cases $(5.5 \%)$ (Plate I, 5) and atrophic and ulceration of the surface epithelium in $2 / 54$ cases $(3.7 \%)$ (Plate I, 6).
The relation of the encountered histopathological urinary bladder changes in relation to sex; locality and age groups as well as their statistical analyses are given (Tabs. 2, $3 \& 4$ ).

Table 2: Histological features in relation to Patients Gender

\begin{tabular}{|l|c|c|c|}
\hline characteristic & \multicolumn{2}{|c|}{ Summary statistics $(\mathrm{N}=54)$} & \multirow{2}{*}{ P value } \\
\cline { 1 - 3 } & Male number $\%$ & Female number $\%$ & \\
Keratinizing & $12(66.7 \%)$ & $6(33.3 \%)$ & \multirow{2}{*}{0.380} \\
Yes & $28(77.8 \%)$ & $8(22.2 \%)$ & \\
\cline { 1 - 2 } Non keratinizing & $16(80 \%)$ & $4(20 \%)$ & \multirow{2}{*}{0.446} \\
Yes & $24(70.6 \%)$ & $10(29.4 \%)$ & \\
No & $7(63.6 \%)$ & $4(36.4 \%)$ & \\
\cline { 1 - 2 } Invasive squamous & $33(82.5 \%)$ & $7(17.5 \%)$ & 0.396 \\
Yes & & & \multirow{2}{*}{0.165} \\
No & $5(100 \%)$ & $0(0 \%)$ & \\
\hline Others & $35(71.4 \%)$ & $14(28.6 \%)$ & \\
Yes & No & & \\
No & & & \\
\hline
\end{tabular}

No significant difference between histological feature and patients' sex

Table 3: Histological features in relation to patient locality

\begin{tabular}{|c|c|c|c|}
\hline \multirow[t]{3}{*}{ characteristic } & \multicolumn{2}{|c|}{ Summary statistics $(\mathrm{N}=54)$} & \multirow[t]{3}{*}{$\mathrm{P}$ value } \\
\hline & Urban & Rural & \\
\hline & No $\%$ & No $\%$ & \\
\hline Gender & & & \\
\hline Males & $7(17.5 \%)$ & $33(82.5 \%)$ & $0.0000 * *$ \\
\hline females & $3(21.4 \%)$ & $11(78.6 \%)$ & \\
\hline Keratinizing & & & \\
\hline Yes & $1(5.6 \%)$ & $17(94.4 \%)$ & 0.083 \\
\hline No & $9(25 \%)$ & $27(75 \%)$ & \\
\hline Non keratinizing & & & \\
\hline Yes & $5(25 \%)$ & $15(75 \%)$ & 0.347 \\
\hline No & $5(14.7 \%)$ & $29(85.3 \%)$ & \\
\hline Invasive squamous & & & \\
\hline Yes & $1(9.1 \%)$ & $10(90.9 \%)$ & 0.367 \\
\hline No & $9(20.9 \%)$ & $34(79.1 \%)$ & \\
\hline Others & & & \\
\hline Yes & $3(60 \%)$ & $2(40 \%)$ & $0.012 *$ \\
\hline No & $7(14.3 \%)$ & $42(85.7 \%)$ & \\
\hline
\end{tabular}

*significant; **very high significant difference between patients sex \& locality.

Table 4: Histological features in relation to age group

\begin{tabular}{|l|c|c|c|c|}
\hline $\begin{array}{l}\text { Histological } \\
\text { feature }\end{array}$ & $\begin{array}{c}\text { N. keratinizing Sq. } \\
\text { metaplasia }\end{array}$ & $\begin{array}{c}\text { Keratinizing Sq. } \\
\text { metaplasia }\end{array}$ & $\begin{array}{c}\text { invasive Sq. } \\
\text { carcinoma }\end{array}$ & others \\
\hline $20-35$ years old & $1(1.9 \%)$ & $3 / 54(5.6 \%)$ & $1(1.9 \%)$ & $3 / 54(7.4 \%)$ \\
\hline $36-45$ years old & $8 / 54(14.8 \%)$ & $9 / 54(16.7 \%)$ & $1 / 54(1.9 \%)$ & $1 / 54(1.9 \%)$ \\
\hline $46-60$ years old & $11 / 54(20.4 \%)$ & $6 / 54(11.1 \%)$ & $9 / 54(16.7 \%)$ & $1(1.9 \%)$ \\
\hline Total & $20 / 54(37 \%)$ & $18 / 54(33.3 \%)$ & $11 / 54(20.4 \%)$ & $5 / 54(9.3 \%)$ \\
\hline P value & P value $=0.296$ & P value=0.197 & P value $=0.056$ & P value $=0.011 *$ \\
\hline
\end{tabular}

* significant, Relation of histopathological features and age groups non- significant

\section{Discussion}

Urinary schistosomiasis is an acute and chronic disease caused by S. haematobium.
Patients are infected during routine agricultural, domestic, occupational and recreational activities which expose them to in- 
fested water (WHO, 2016). In general, transmission tends to be higher in rural than urban areas (Clements et al, 2006).

Adult schistosomes do not usually cause an inflammatory reaction in the venous system. In fact, their presence is associated with increased protection of the host against reinfection by cercariae. In general, dead eggs and dead flukes cause a more severe inflammatory reaction than living ones do (Gryseels et al, 2006).

Deposition of Schistosoma eggs in the bladder causes eosinophilic inflammation, necrosis and ulceration, followed by fibrosis with chronic inflammatory infiltrate (Al-Hussain, 2015), Pathological changes in the urinary tract due to schistosomiasis are far more common in chronic infections than in acute ones, these chronic lesions induces granuloma formation (Moudgil and Kosut, 2007; Shebel et al, 2012). Moreover, the bladder cancer continued to be the most common cancer among men in Egypt and the most common cause of death in men aged 20-40 years (Freedman et al, 2006, Farlay et al, 2010).

In the Middle and Upper Egypt, there was consistent reduction in the prevalence of S. haematobium except in Sohag, Qena, and Aswan Governorates (El Khoby et al, 2000; Barakat, 2013; Dahesh and Farid, 2016), where there was a dramatic increase in these three governorates following the construction of the High Dam where the basin irrigation was converted to perennial irrigation system (Barakat, 2013).

In the present study, 54 bladder specimens examined at Department of Pathology were diagnosed as chronic schistosomiasis haematobium. Chronic irritation of the urothelium causes it to proliferate; producing budlike or polyploidy structures. These structures differentiate into cystic deposits of cystitis cystica, which is considered as a precursor of bladder cancer (Raja et al, 2003; Shebel et al, 2012; Parakh, 2013). Bacteria that usually accompany schistosomiasis can also promote formation of carcinogenic components as Nnitrosamines (Zaghloul, 2012).

Squamous metaplasia of the bladder is replacement of the urothelium by stratified squamous epithelium, there are both nonkeratinized and keratinized subtypes, schistosomiasis is one of the causes of this metaplasia. Keratinized subtypes are considered a risk factor for squamous cell carcinoma (Parakh, 2013).

Urinary schistosomiasis was first linked to urinary bladder cancer by Furgesson in Egypt in 1911.The incidence of urinary bladder cancer in Middle East and Africa is greater in areas with high rather than low S. heamatobium prevalence (Ministry of Health and Population, 2004). It is surprising that Lopes et al. (2006) and Casella et al. (2009) reported that $S$. mansoni was the cause of bladder neoplasia, but this can be due to the very rare ectopic invasion of the urinary system by $S$. mansoni.

In geographic regions where schistosomiasis is not endemic, squamous cell carcinomas account for less than $5 \%$ of all bladder malignancies (Murphy et al., 2004); while in areas where schistosomiasis is endemic there is a high incidence of squamous cell carcinoma of the urinary bladder (Shokeir, 2004, Ketabchi and Moshtaghi-Kashanian, 2012; Rambau et al, 2013 ), which accounted for more than $50 \%$ of bladder cancers (Shokeir, 2004).

However, in Sudan, Obzey (2015) reported only $5 \%$ cases of squamous cell carcinoma were due to urinary schistosomiasis.

The urinary bladder cancer previously accounted for about $31 \%$ of the total incidence of cancers in Egypt that subsequently decreased to $12 \%$ in recent years. Bilharzia association dropped from $82.4 \%$ to $55.3 \%$ leading to change in the urinary bladder carcinoma with significant predominance of transitional cell carcinoma (Gouda et al, 2007). Khaled (2013) also detected that the frequency rate of bladder cancer has declined significantly during the last 25 years. This decline was associ- 
ated with a decline in bilharzial egg positivity in the specimens and is probably related to better control of schistosomiasis in the region. This reduction was accompanied by a change in the histological profile of tumors with a significant predominance of transitional cell carcinoma and an increase in the age of patients; a pattern rather similar to that in western reports (Gouda et al, 2007; Felix et al, 2008; Khaled, 2013).

Histopathological examination of biopsy specimens of the bladder lesions in the present study revealed that squamous metaplasia of the urinary bladder in $(70.4 \%)$ : $37 \%$ non-keratinizing metaplasia and $33.3 \%$ keratinizing metaplasia but, $20.4 \%$ cases of the urinary bladder with schistosomiasis showed invasive squamous carcinoma. This disagreed with Idrees (2015) who detected that Sudan and Egypt have the highest incidence of schistosomiasis, where squamous cell carcinoma ranged from two thirds to three quarters of all malignant tumors of the bladder. According to Muraliet al. (2002), Ahmad et al. (2008) and Jukiewicz and Zabkowski (2014) non keratinizing metaplasia is benign to have no malignant potential while keratinizing metaplasia is a definite precursor of the carcinogenesis. Hence, symptomatic and proper anti-sch-istosomal treatment may improve the quality of the life and disease prognosis of cases of non-keratinizing metaplasia.

On the other hand, keratinizing squamous metaplasia has increased risk of neoplasia especially in patients with extensive lesions with the intra-epithelial neoplasia. Moreover, the non-keratinizing metaplastic cases should be carefully followed up with urinary cytology and cystoscopy for few years after the schistosomaisis management (Jukiewicz and Zabkowski, 2014).

The present results did not agree with those of Felix et al. (2008), Salem and Mahfouz (2012) who recorded a changing behavior of schistosomal bladder cancer as transitional cell carcinoma has become the most frequent type.

In the present study there was no significant difference between age groups and the 3 histological subtypes; although it was evident that all the three subtypes of metaplasia were more common in older and middle aged than younger patients. This agreed with Zepeda and Coffey (2015) who reported $S$. haematobium infection that mimicked bladder cancer in a 66 year old Egyptian patient. However, this squamous metaplasia subtypes should be notified in future works as they are important criteria for cases management.

As urinary schistosomiasis is the main cause of urinary bladder carcinoma all efforts must be directed towards the near future control measures of this disease in Sohag Governorate as well as other endemic areas.

\section{Conclusion}

Schistosoma haematobium is still one of the major risks of developing squamous cell metaplasia of the urinary bladder in Egypt which was found to be most prevalent in rural areas.

In this study, bladder squamous metaplasia was divided into non-keratinizing with less malignant potential, keratinizing with a definite affinity to carcinogenesis and invasive severe forms; but these subdivisions were found to be statistically not significant in relation to gender, age and locality

\section{References}

Ahmad, I, Barneetson, R, Krishna, N, 2008: Keratinizing squamous metaplasia of the bladder: A review. Urol. Int. 81:247-51.

Al-Hussain, T, 2015: Schistosomiasis-related cystitis Revised: http://www. Pathologyonlines. com/topic/bladderschistosomiasis.htlm

Barakat, RMR, 2013: Epidemiology of schistosomiasis in Egypt: Travel through time. Rev. J. Adv. Res. 4, 5:425-32.

Barsoum, RS, 2013: Urinary schistosomiasis: Review. J. Adv. Res., 4, 5:453-59.

Barsoum, RS, Esmat, G, El-Bazb, T, 2013: Human schistosomiasis: Clinical perspective: Review. J. Adv. Res. 4, 5:433-44. 
Casella, M, Fanni, V, Vernd, ID, et al, 2009: Schistosomia mansoni of the bladder simulating bladder cancer: a case report. Rev. Soc. Brasi. Med. Trop., 42, 5:581-2.

CDC, 2011: The Burden of schistosomiasis. Available: http://www.cdc.gov/globalhealth/ ntd/diseases/schisto_burden.html.

Clements, AC, Moyeed, R, Brooker, S, 2006: Bayesian geostatistical prediction of the intensity of infection with $S$. mansoni in East Africa. Parasitol. 133, 6:711-9.

Culling, CFA, 1993: Handbook of Histological and Histochemical Techniques. $3^{\text {rd }}$ Ed., Butterworth, London, Boston.

Dahesh, S, Farid, B, 2016: Epidemiological status of urinary schistosomiasis in Tamwah, Giza, Egypt: assessment and control. J. Egypt. Soc. Parasitol. 48, 3:485-96.

Daniel, A, Blatt, A, 2016: Schistosoiasis and bladder cancer in Egypt: A historical analysis. J. Global Onchol, 50s Abstract.

El Khoby, T, Galal, N, Fenwick, A, Barakat, R, El Hawy, A, et al, 2000: The epidemiology of schistosomiasis in Egypt: Summary findings in nine governorates. Am. J. Trop. Med. Hyg. 62, 2:88-99.

El-Sebaie, M, Zaghloul, MS, Howard, G, Mokhtar, A, 2005 Squamous cell carcinoma of the bilharzial and non-bilharzial urinary bladder: A review of etiological; features, natural history and management. Internat. J. Clin. Oncol. 10, 1:20-5.

Farlay, J, Shin, H, Bray, E, et al, 2010: Estimates of worldwide burden of cancer in 2008: Int. J. Cancer 127:2893-17.

Felix, AS, Soliman, AS, Khaled, H, Zaghloul, MS, Banerjee, M, El-Banerjee, M, et al, 2008: The changing patterns of bladder cancer in Egypt over the past 26 years. Cancer Causes Control, 19, 4:421-9.

Ferguson, AR, 1911: Associated bilharziasis and primary malignant disease of the urinary bladder with observations on a series of forty cases. J. Path. Bact., 16:76-94.

Freedman, LS, Edward, BK, Ries, LA, et al., 2006: Cancer Incidence in Four Countries (Cyprus, Egypt, Israel and Jordan) of the Middle East Cancer Consortium (MECC) compared with US Seer. Ed., NCI, USA.

Gouda, I, Mokhtar, N, Bilal, D, El-Bolkainy, T, El-Bolkainy, MN, 2007: Bilharziasis and bladder cancer: a time trend analysis of
9843 patients J. Egypt. Natl. Canc. Inst. 19, 2: 158-62

Gryseels, B, Polman, K, Clerinx, J, Kestens, L, 2006: Human schistosomiasis: www. thelan cet.com, 368, 9541:1106-18.

Idrees, MT, 2015: Pathology of Urinary Bladder Squamous Cell Carcinoma: Overview of Squamous Cell Bladder Carcinoma. Drugs and Diseases, Pathology, Medscape.com

Jurkiewicz, B, Zabkowski, T, 2014: Nonkeratinised squamous metaplasia of the urinary bladder in children: A report of case experience. Biomed Res. Internat. Open access article ID 936970, 6 pages.

Ketabchi, AA, Moshtaghi-Kashanian, GR, 2012: Urinary schistosomiasis with simultaneous bladder squamous cell carcinoma and transitional cell carcinoma, Iran. J. Parasitol. 7, 3: 96-8.

Khaled, H, 2013: Schistosomiasis and cancer in Egypt: Rev. J. Adv. Res, 4, 5: 461-66.

Lopes, E, Santos, T, Martins, V, 2006: $S$. mansoni simulating bladder neoplasia. Rev. Soc. Bras. Med. Trop. 39, 3:1-4.

Ministry of Health and Population, 2004: Department of Endemic Diseases, Prevalence of Schistosomiasis in Egypt Over Time, Egypt. Moudgil, A, Kosut, J, 2007: Urinary schistosomiasis: an uncommon cause of gross hematuria in the industrialized countries. Pediatr. Nephrol. 22, 8:1225-7.

Murali, K, Ankem, MD, Aaron, B, et al, 2002: Non-keratinizing squamous metaplasia of the bladder in children. Infect. Urol. 15, 4:13.

Murphy, WM, Grignon, DJ, Perlman, EJ, 2004: Tumors of the Kidney, Bladder, and Related Urinary Structures. Washington, DC: American Registry of Pathology, 394.

Ozbey, EG, 2015: Squamous cell carcinoma in bladder secondary to $S$. haematobium infection. Edorium. J. Infect. Dis. 2:7-10.

Parakh, R, 2013: Bladder Metaplasia Squamous Metaplasia Pathology Outlines.com Raja, J, Anson, K, Patel, U, 2003: Cystitis cystica and glandularis: Presentation with acute ureteric obstruction. Alin. Radiol. Extra 58 :43-4.

Rambau, PF, Chalya, PL, Jackson, K, 2013: Schistosomiasis and urinary bladder cancer in North Western Tanzania: A retrospective review of 185 patients Infect. Agents Cancer 8:19-25. 
Salem, HK, Mahfouz, S, 2012: Changing patterns (age, incidence and pathologic types) of Schistosoma-associated bladder cancer in Egypt in the past decade. Oncol. 79:379-83.

Shebel, HM, Elsayes, KM, Abou El Atta, H M, Elguindy, YM, El-Diasty, TA, 2012: Genitourinary schistosomiasis: Life cycle and radiologic-pathologic findings. Radiographics 32, 4:1031-46

Shokeir, AA, 2004: Squamous cell carcinoma of the bladder: pathology, diagnosis and treatment. BJU Int. 93, 2:216-20.
WHO, 2016: Ten Facts About Schistosomiasis Updated January 2016.

Zaghloul, MS, 2012: Bladder cancer and schistosomiasis. J. Egypt. Nat. Cancer Instr. 24:151-9.

Zepeda, C, Coffey, K, 2015: S. haematobium infection that mimics bladder cancer in a 66year -old ethnic Egyptian man. Lab. Med., 46, $4: 338-42$.

\section{Legend of Fingers}

Plate I: Histopathological changes in the urinary bladder due to Schistosoma haematobium infection.

Fig. 1: Keratinizing Squamous metaplasia of surface epithelium of urinary bladder with subepithelial bilharzial eggs deposition

Fig. 2: Non Keratinizing Squamous metaplasia of surface epithelium of urinary bladder with subepithelial bilharzial eggs deposition

Fig. 3: Invasive Squamous cell carcinoma of urinary bladder with large number of bilharzial eggs deposition reaching muscle layer.

Fig. 4: Schistosoma eggs surrounded by group of Invasive Squamous cell carcinoma and chronic inflammatory cells.

Fig. 5: Atrophy of the surface epithelium of urinary bladder, with formation of cystitis cystica and brunn's nests with subepithelial bilharzial ova deposition.

Fig. 6: Ulceration of surface epithelium of urinary bladder with subepithelial bilharzial eggs deposition. 


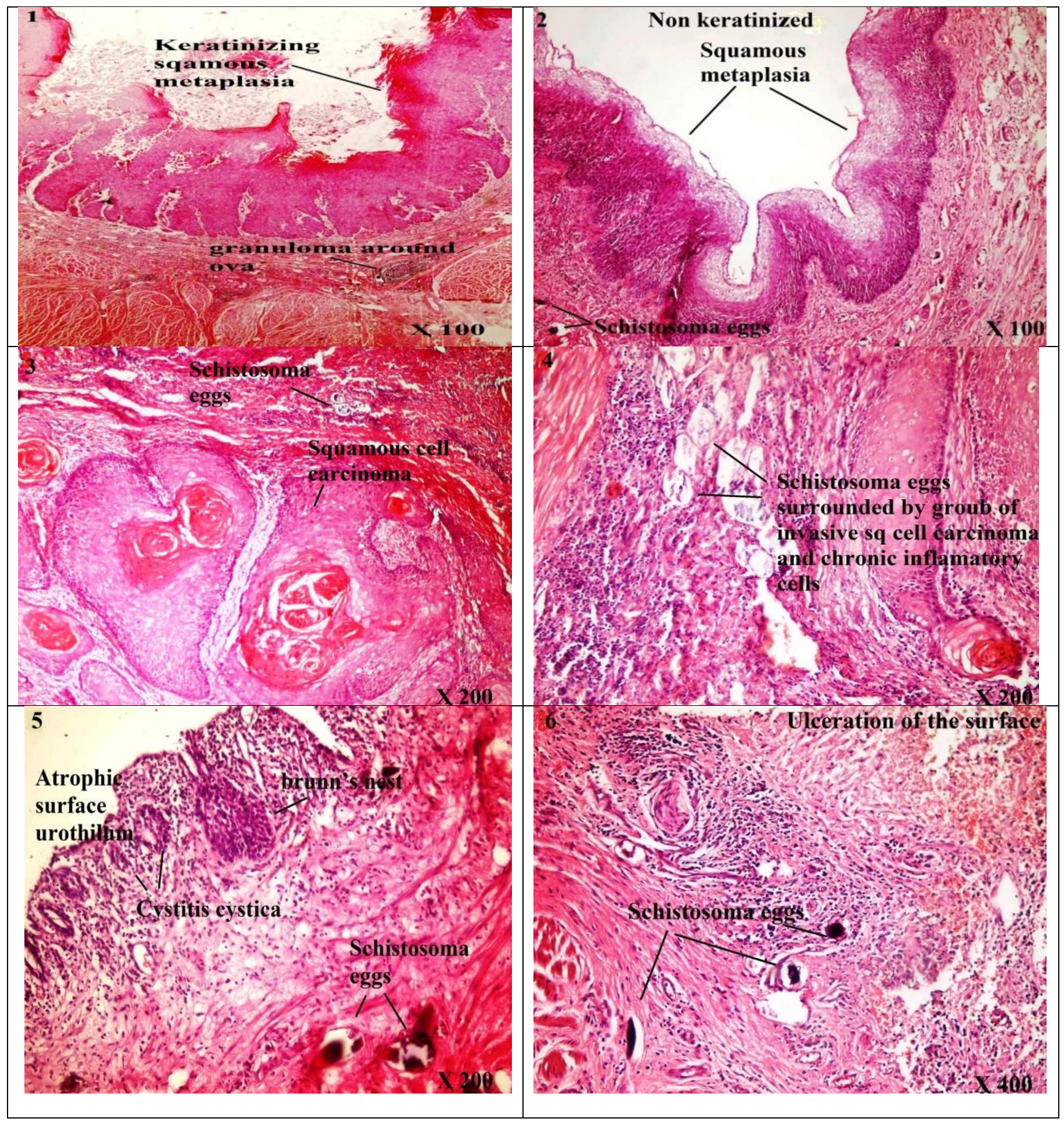

